\title{
Pregled stanja kožarsko-prerađivačke industrije za razdoblje 2008. - 2019. i u vrijeme pandemije zbog korona virusa COVID-19 u 2020.
}

Jagoda Divić, univ. spec. oec.

Hrvatska gospodarska komora, Sektor za industriju

Nova cesta 7, 10000 Zagreb

jdivic@hgk.hr

\section{Sažetak}

Dan je pregled osnovnih statističkih pokazatelja kožarsko-prerađivačke industrije za period 2008-2019. te za razdoblje prvih 8 mjeseci 2020. god. Kožarskoprerađivačka industrija radno je intenzivna i izvozno usmjerena industrija koja zapošljava oko 10.000 ljudi. Uspoređujući statističke pokazatelje zadnjih 10 godina, prema broju zaposlenih i ukupnom prihodu, uočeno je da je ova industrijska grana imala najbolje financijske pokazatelje 2015. godine, nakon toga bilježi uglavnom pad do 2019. god. Industrijska proizvodnja je zbog pandemije korona virusa Covid-19 u prvih 8 mjeseci 2020. ukupno pala za 4,7\%, prerađivačka ukupno za 5,4 \%, dok je kožarsko-pređivačka industrijala pala 3 puta više tj. za 15,6 \% u odnosu na isto razdoblje 2019. god. Neto prosječna plaća u 2019. god. je u odnosu na 2015. porasla za $28,1 \%$, dok u 2019. u odnosu na ukupno prerađivačku industriju zaostaje god. za $26,0 \%$. Postoji nedostatak radne snage, posebno stručno obrazovane, zbog prirodnog odljeva odnosno odlaska u mirovinu starijih zaposlenika te slabije motivacije mlađih ljudi koji poslove traže u nekim bolje plaćenim industrijama ili pak u inozemstvu.

Ključne riječi: koža, kožarsko-prerađivačka industrija, obuća, pregled

\section{Uvod}

U Hrvatskoj gospodarskoj komori (HGK) u Sektoru za industriju djeluje Udruženje kožarsko-prerađivačke industrije čije su članice sve tvrtke registrirane za djelatnost C15 - Proizvodnja kože i srodnih proizvoda. U 2019. godini u RH registrirano je 155 tvrtki za proizvodnju kože i proizvoda od kože. Je 97 mikro tvrtki, 33 male tvrtke, 3 srednje i 2 velike tvrtke. Od ukupnog broja tvrtki, njih 62 registrirane su u djelatnost C15.1-Štavljenje i obrada kože; proizvodnja putnih i ručnih torbi, dorada i bojenje krzna, dok su 73 tvrtke registrirane za djelatnost C15.2 - proizvodnju obuće. Industrija kože i kožnih proizvoda u posljednjih nekoliko mjeseci bilježi kontinuiran pad proizvodnje zbog pandemije Covid 19. Kožarsko.prerađivačka industrija je radno intenzivna i usmjerena je uglavnom prema tržištu Europske unije. Najveći dio svojih proizvoda izvozi na tržište u okruženju i na tržište Eurpske unije. Zahtjevi tržišta su sve veći u smislu povećanja kvalitete kožarskih i obućarskih proizvoda te se pred poslovnim subjektima sve više nameće potreba stalnog poboljšanja kvalitete.

\section{Broj zaposlenih, broj tvrtki, prihodi i plaće u kožarsko-prerađivačkoj industriji RH}

U 2019. godini bilo je zaposleno 9.989 osoba, a taj se broj u posljednjih 10 godina (od krizne 2009. god.) povećao za 29,9 \% (sl. 1). U odnosu na 2018. (9.643) god., broj zaposlenih se u 2019. god. ipak povećao za (9.642) za $3,6 \%$ (347 osobe), a razlog tome je povećan broj tvrtki sa 142 na 155 (sl. 2). Iz tablice 2 vidljivo je također da je broj tvrtki u razdoblju od 2008 do 2019. povećan sa 124 na 155 ili za $25 \%$.

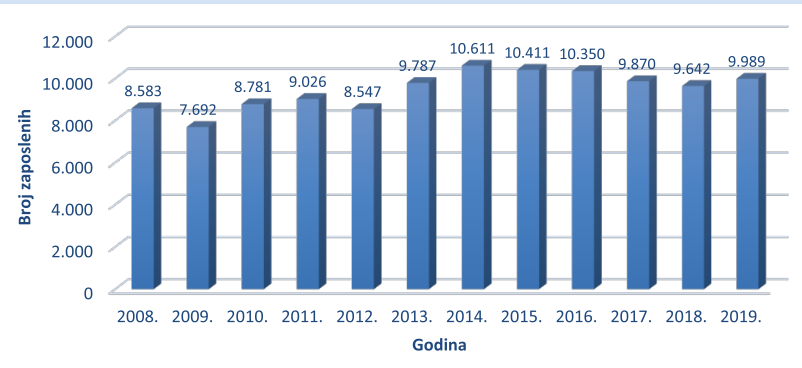

SI. 1 Broj zaposlenih u kožarsko-prerađivačkoj industriji u Republici Hrvatskoj za razdoblje 2008-2019

Na slici 3 prikazani su ukupni prihodi po godinama za razdoblje 2008-2019. Vidljivo je da da su najmanji prihodi bili u razdoblju krize 2008 i 2009. god. 315,3 odn. 291 mil $€$. Nakon 2009. god, dolazi do snažnijeg porasta ukupnih prihoda dosežući maksimum 2015. god. od 504,6 mil. €. Nakon 2015. god. nastaje postupni pad ukupnih prihoda dosežući iznos od 351,6

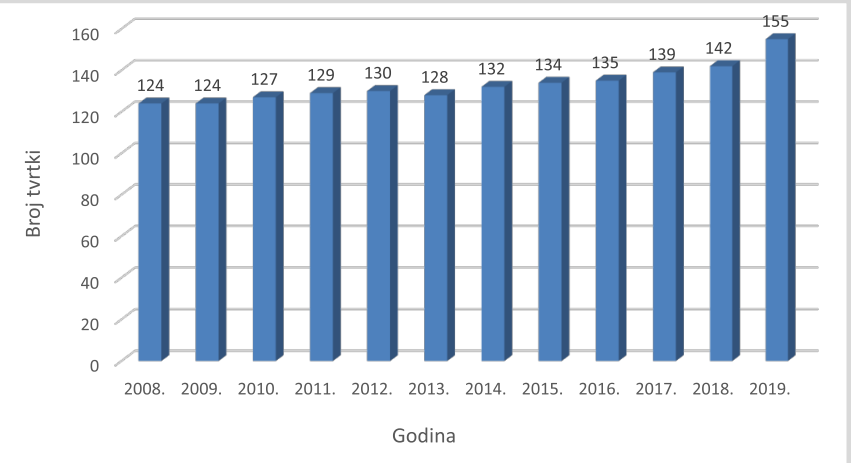

SI. 2 Broj tvrtki kožarsko-prerađivačke industrije u Republici Hrvatskoj za razdoblje 2008-2019

mil. € u 2019. god. Razlog pada ukupnih prihoda treba tražiti i u većoj konkurenciji na tržištu.

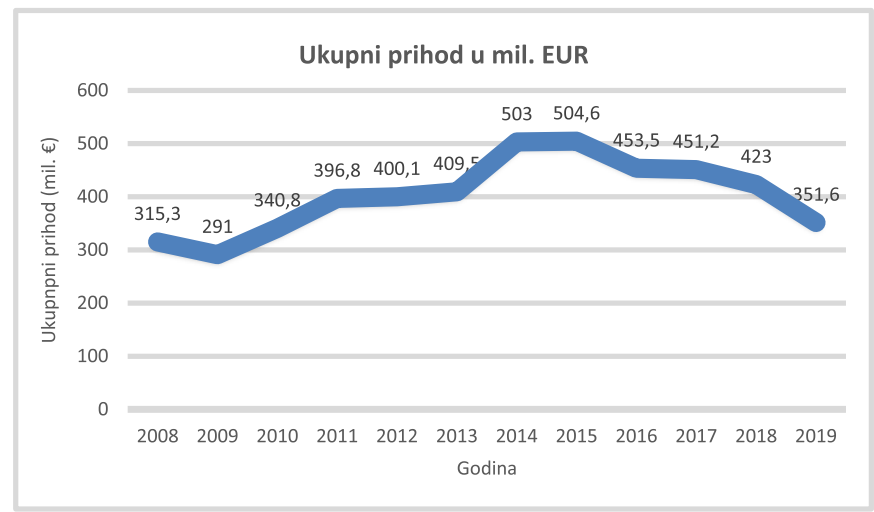

SI. 3 Ukupni prihodi kožarsko-prerađivačke industrije u Republici Hrvatskoj za period 2008-2019

U tablici 1 prikazana je robna razmjena industrije u $\mathrm{RH}$ za 2018 i 2019. u tis. $€$. U kožarsko-prerađivačkoj industriji zabilježen je porast izvoza za 2,3\% iz istovremeni porast uvoza za $5,8 \%$, a kod toga prerađivačka industrija ukupno bilježi porast izvoza za $6,2 \%$ uz porast i uvoza za $9,1 \%$. Dakle, kožarsko prerađivačka industrija bilježi relativno manje promjene u odnosu na prerađivačku industiju ukupno.

U pogledu neto isplaćenih plaća u industriji u RH u razdoblju 2015-2019. god. (tab. 2) uočava se kontinuirani porast. Tako je u kožarskoprerađivačkoj industriji neto plaća u 2019. god. (4.369 kn) u odnosu na neto plaću u 2015. god. (3.409 kn) bila veća za 960 kn ili $28.1 \%$. 
Tablica 1 Robna razmjena po djelatnosti u RH za 2018. i 2019. u $000 €$

\begin{tabular}{|c|c|c|c|c|}
\hline \multirow{2}{*}{ Djelatnost } & \multicolumn{2}{|c|}{ IZVOZ } & \multicolumn{2}{|c|}{ uvoz } \\
\hline & $01 .-12.2018 .0$ & 1. - 12.2019. INDEX O & -12.2018 & 1. - 12.2019. INDEX \\
\hline UKUPNO & 14388459 & 15226703106,2 & 23495430 & 24980960106,3 \\
\hline PRERAĐIVAČKA INDUSTRIJA - C & 12928802 & 13735056106,2 & 20419170 & 22276319109,1 \\
\hline TEKSTIL - C13 & 176770 & 17349298,1 & 446169 & 43837898,3 \\
\hline ODJEĆA-C14 & 686198 & 713942104,0 & 1058001 & 1119036107,0 \\
\hline KOŻA I PROIZVODI OD KOŽE -C15 & 431744 & 441852102,3 & 611563 & 605540105,8 \\
\hline
\end{tabular}

Nadalje, neto plaća u kožarsko-prerađivačkoj industriji je u odnosu na prosječnu plaću u prerađivačkoj industriji (5.940 kn) u RH u prosječno manja za 1.544 kn ili za 26,0 \%. Trend porasta plaća u kožarskoprerađivačkoj industriji jaće izražen u 2019. god. u odnosu na 2018. god., i to za $7,5 \%$.

Tablica 2 Prosječne mjesečne isplaćene neto i bruto plaće po zaposlenom $u$ industriji za period 2015 - 2019

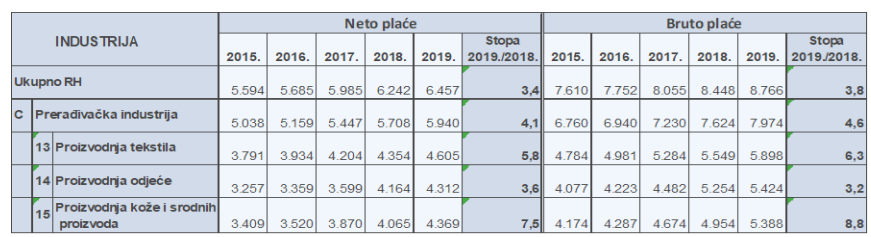

\section{Pregled za vrijeme pandemije zbog korona virusa COVID-19 u 2020.}

Svjetska zdravstvena organizacija proglasila je 11. ožujka 2020. pandemiju zbog koronavirusa COVID-19. Pandemija je znatno utjecala i na poslovanje u 2020. god., kako u svijetu, tako u Republici Hrvatskoj. Proizvodnja u prvih 6 mjeseci 2020. god. u odnosu na prva 6 mjeseca 2019. god., u gotovo svim industrijskim sektorima je pala, pa tako i u kožarsko-prerađivačkoj industriji (sl. 4).

INDEKSI FIZIČKOG OBUJMA INDUSTRIJSKE PROIZVODNJE RH I-VI 2020/I-VI 2019.

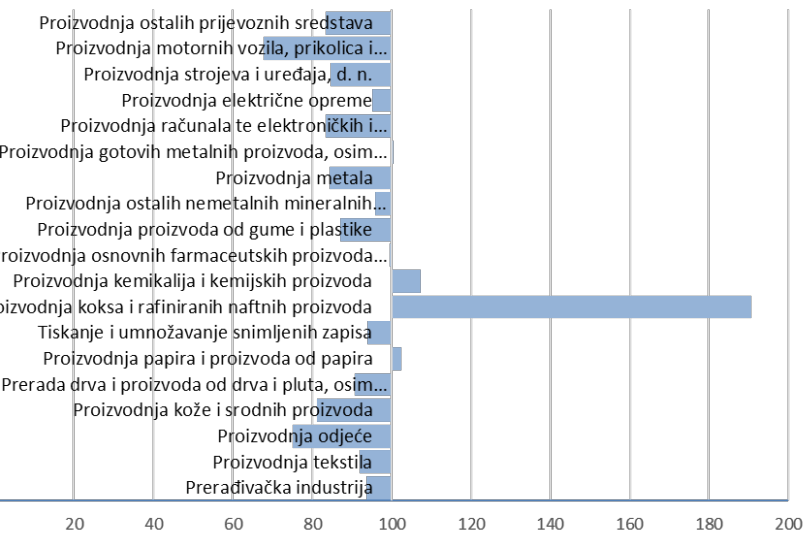

Slika 4. Indeksi fizičkog obujma industrijske proizvodnje RH u periodu I-VI 2020/IVI 2019 u vrijeme pandemije Covid-19

Detaljniji prikaz stanja industrijske aktivnosti u RH u 2020. god. za prvih 8 mjesecu dan je u tablici 3. Pad proizvodnje u kožarsko-prerađivačkoj industriji u 2020. god. u odnosu na 2019. god. iznosio je 15,6 \%, uz istovremeni pad ukupne industrijske proizvodnje za $4,7 \%$ a prerađivačke industrije za 5,4 \%. Dakle, kožaraskoprerađivačka industrija bilježi znatno veći pad, 3 puta veći od prosjeka pada industrijske proizvodnje odnosno prerađivačke industrije.

Stopa zaposlenosti u kožarsko-prerađivačkoj industriji (uključe vrijeme padnemije zbog korona virusa COVID-19) u VIII. mjesecu 2020. u odnosu na VIII. mjesec 2019. god. pala je za 3,4 \% (tab. 4), dok istovremeno stopa zaposlenosti za cijelu prerađivačku industriju bilježi pad od 1,5\%. Manji porast broja zaposlenih treba uzeti vezano za odlazak u mirovinu.
Tablica 3 Indeks industrijske proizvodnje u RH za period od 8 mjeseci I-VIII 2020/IVIII 2019 u vremenu pandemije COVID-19

\begin{tabular}{|c|c|c|}
\hline Industrijska djelatnost & Struktura & $\begin{array}{l}\text { Indeks I-VIII 2020/I-VIII } \\
2019\end{array}$ \\
\hline Ukupno industrija & 100 & 95,3 \\
\hline Prerađivačka industrija & 81,9 & 94,6 \\
\hline \begin{tabular}{|l|} 
Proizvodnja \\
prehrambenih \\
proizvoda \\
\end{tabular} & 15,1 & 97,6 \\
\hline Proizvodnja pića & 5,2 & 80,2 \\
\hline $\begin{array}{l}\text { Proizvodnja duhanskih } \\
\text { proizvoda }\end{array}$ & 0,4 & 86,5 \\
\hline Proizvodnja tekstila & 1 & 90,7 \\
\hline Proizvodnja odjeće & 2 & 75,2 \\
\hline $\begin{array}{l}\text { Proizvodnja kože i } \\
\text { srodnih proizvoda }\end{array}$ & 1,5 & 84,4 \\
\hline $\begin{array}{l}\text { Prerada drva i } \\
\text { proiuvoda od drva i } \\
\text { pluta, osim namještaja; } \\
\text { proizvodnja proizvoda } \\
\text { od slame i pletarskim } \\
\text { materijala. }\end{array}$ & 4 & 90,5 \\
\hline $\begin{array}{l}\text { Proizvodnja papira i } \\
\text { proizvoda od papira }\end{array}$ & 2,4 & 100,1 \\
\hline $\begin{array}{l}\text { Tiskanje i umnožavanje } \\
\text { tiskanih zapisa }\end{array}$ & 1,5 & 93,6 \\
\hline $\begin{array}{l}\text { Proizvodnja koksa i } \\
\text { rafiniranih naftnih } \\
\text { proizvoda }\end{array}$ & 1,8 & 129,3 \\
\hline $\begin{array}{l}\text { Proizvodnja kemikalija i } \\
\text { kemijskih proizvoda }\end{array}$ & 2,3 & 109,2 \\
\hline $\begin{array}{l}\text { Proizvodnja osnovnih } \\
\text { farmaceutskih } \\
\text { proizvoda i } \\
\text { farmaceutskih } \\
\text { pripravaka } \\
\end{array}$ & 5,8 & 101,3 \\
\hline $\begin{array}{l}\text { Proizvodnja proizvoda } \\
\text { od gume i plastike }\end{array}$ & 4,8 & 88,5 \\
\hline $\begin{array}{l}\text { Proizvodnja ostalih } \\
\text { nemetalnih mineralnih } \\
\text { proizvoda }\end{array}$ & 6,6 & 97,7 \\
\hline Proizvodnja metala & 2,2 & 87,6 \\
\hline \begin{tabular}{|l}
$\begin{array}{l}\text { Proizvodnja gotovih } \\
\text { metalnih proizvoda } \\
\text { osim strojeva i opreme }\end{array}$ \\
\end{tabular} & 7,7 & 102,7 \\
\hline $\begin{array}{l}\text { Proizvodnja računala te } \\
\text { elektroničkih i optičkih } \\
\text { proizvoda }\end{array}$ & 1,5 & 89,7 \\
\hline $\begin{array}{l}\text { Proizvodnja električne } \\
\text { opreme }\end{array}$ & 4 & 96 \\
\hline $\begin{array}{l}\text { Proizvodnja strojeva i } \\
\text { uređaja }\end{array}$ & 3,2 & 86,9 \\
\hline $\begin{array}{l}\text { Proizvodnja motornih } \\
\text { vozila, prikolica i } \\
\text { poluprikolica } \\
\end{array}$ & 1 & 75,1 \\
\hline $\begin{array}{l}\text { Proizvodnja ostalih } \\
\text { prijevoznih sredstava }\end{array}$ & 0,5 & 92,3 \\
\hline Proizvodnja namještaja & 2,5 & 84 \\
\hline $\begin{array}{l}\text { Ostala prerađivačka } \\
\text { industrija }\end{array}$ & 0,8 & 84,7 \\
\hline $\begin{array}{l}\text { Popravak i instaliranje } \\
\text { strojeva i opreme }\end{array}$ & 4,1 & 101,3 \\
\hline
\end{tabular}


Tablica 4 Zaposlenost u VIII. mjesecu 2020 u odnosu na VIII. mjesec 2019.

\begin{tabular}{|c|c|c|c|c|c|}
\hline \multirow{2}{*}{\multicolumn{2}{|c|}{\begin{tabular}{|l|} 
\\
Ukupno:
\end{tabular}}} & \multirow{3}{*}{$\begin{array}{c}\text { VIII. } 2019 . \\
1341924 \\
228521\end{array}$} & \multirow{3}{*}{\begin{tabular}{|c|} 
VIII. 2020. \\
1315534 \\
225036
\end{tabular}} & \multirow{3}{*}{$\begin{array}{c}\begin{array}{c}\text { Stopa rasta VIII./I } \\
\text { VIII., \% }\end{array} \\
-2,0 \\
-1,5\end{array}$} & \multirow{3}{*}{$\begin{array}{c}\begin{array}{c}\text { Ukupom broju } \\
\text { VIII. 2020. }\end{array} \\
100,0 \\
17,1\end{array}$} \\
\hline & & & & & \\
\hline C & Prerađivačka industrija & & & & \\
\hline 10 & Proizvodnja prehrambenih proizvoda & 42791 & 41658 & $-2,6$ & 3,2 \\
\hline 11 & Proizvodnja pića & 5356 & 5137 & $-4,1$ & 0,4 \\
\hline 12 & Proizvodnja duhanskih proizvoda & 926 & 858 & $-7,3$ & 0,1 \\
\hline 13 & Proizvodnja tekstila & 3226 & 3147 & $-2,4$ & 0,2 \\
\hline 14 & Proizvodnja odjeće & 11715 & 11452 & $-2,2$ & 0,9 \\
\hline 15 & Proizvodnja kože i srodnih proizvoda & 9755 & 9423 & $-3,4$ & 0,7 \\
\hline 16 & $\begin{array}{l}\text { Prerada drva i proizvoda od drva i pluta, osim } \\
\text { namještaja; proizvodnja proizvoda od slame i } \\
\text { pletarskih materijala }\end{array}$ & 14447 & 14682 & 1,6 & 1,1 \\
\hline 17 & Proizvodnja papira i proizvoda od papira & 4571 & 4596 & 0,5 & 0,3 \\
\hline 18 & Tiskanje i umnožavanje snimljenih zapisa & 6486 & 6391 & $-1,5$ & 0,5 \\
\hline 19 & Proizvodnja koksa i rafiniranih naftnih proizvoda & 1265 & 1187 & $-6,2$ & 0,1 \\
\hline 20 & Proizvodnja kemikalija i kemijskih proizvoda & 5541 & 5565 & 0,4 & 0,4 \\
\hline 21 & $\begin{array}{l}\text { Proizvodnja osnovnih farmaceutskih proizvoda i } \\
\text { farmaceutskih pripravaka }\end{array}$ & 4970 & 5269 & 6,0 & 0,4 \\
\hline 22 & Proizvodnja proizvoda od gume i plastike & 10220 & 10158 & $-0,6$ & 0,8 \\
\hline 23 & Proizvodnja ostalih nemetalnih mineralnih proizvoda & 10803 & 10851 & 0,4 & 0,8 \\
\hline 24 & Proizvodnja metala & 4484 & 4381 & $-2,3$ & 0,3 \\
\hline 25 & $\begin{array}{l}\text { Proizvodnja gotovih metalnih proizvoda, osim strojeva } \\
\text { i opreme }\end{array}$ & 30445 & 29456 & $-3,2$ & 2,2 \\
\hline 26 & $\begin{array}{l}\text { Proizvodnja računala te elektroničkih i optičkih } \\
\text { proizvoda }\end{array}$ & 5617 & 3218 & $-42,7$ & 0,2 \\
\hline 27 & Proizvodnja električne opreme & 10804 & 10403 & $-3,7$ & 0,8 \\
\hline 28 & Proizvodnja strojeva i uređaja, d. n. & 11532 & 10741 & $-6,9$ & 0,8 \\
\hline 29 & Proizvodnja motornih vozila, prikolica i poluprikolica & 3650 & 4043 & 10,8 & 0,3 \\
\hline 30 & Proizvodnja ostalih prijevoznih sredstava & 5189 & 5221 & 0,6 & 0,4 \\
\hline 31 & Proizvodnja namještaja & 10416 & 9724 & $-6,6$ & 0,7 \\
\hline 32 & Ostala prerađivačka industrija & 2800 & 2913 & 4,0 & 0,2 \\
\hline 33 & Popravak i instaliranje strojeva i opreme & 11512 & 14562 & 26,5 & 1,1 \\
\hline
\end{tabular}

Vrijednost izvoza kožarsko prerađivačke industrije za razdoblje I.-VII. 2020 je iznosila 235,7 mil. $€$, i manja je u odnosu na isto razdoblje 2019. za $11.2 \%$ (tab. 5). Uvoz je 2020. god. iznosio 315,4 mil. € i također je manji u odnosu na isto razdoblje 2019. god. za 13,2 \%. Ukupno prerađivačka industrija je bilježila pad izvoza za 11,6 \% i pad uvoza za 12,3 \%. Razlog pada izvoza i uvoza je slabija potražnja na tržištu uzrokovana pandemijom korona virusa Covid-19.

\section{ZAKLJUČAK}

Prednosti kožarsko-prerađivačke industrije RH jesu:

- educirana i iskusna radna snaga,

- poštivanje roka isporuke gotove robe,

- visoka kvaliteta izrade,

- tradicija u proizvodnji,

- povoljni geostrateški položaj i mogućnost transporta morskim putem,

- izrazita izvozna usmjerenost,

- $\quad$ otvorenost za suradnju sa svijetom

Ključne slabosti domaće industrije kože i obuće jesu:

- nerazvijeni marketinški (tržišni) procesi,

- nerazvijena marketinška strategija,

- niska profitabilnost

- nedostatak kapitalne opremljenosti domaćih proizvođača,

- visoki troškovi proizvodnje,

- nedovoljan broj stručnih kadrova, posebice dizajnera, modelara, tehnologa,

- nepostojanje maloprodajnih i internetskih kanala,

- niska produktivnost i učinkovitost.

Pet ključnih faktora uspjeha u proizvodnji proizvoda od kože za tržište Europske unije jesu:

1. kvalitetan dizajn,

2. kvalitetan proizvod,

3. konkurentna cijena proizvoda,
4. komunikacija s kupcima,

5. upravljanje kanalima distribucije.

Očekuje se da će se pozitivan trend rasta i ulaganja u kožarsko-prerađivačku industriju nastaviti i u sljedećim godinama. Hrvatska gospodarska komora, svjesna činjenice da industriji nedostaje specifično educiran kadar, u suradnji s HOK-om kroz uvođenje hrvatskog modela dualnog obrazovanja i učenja za poduzetništvo želi strukovno obrazovanje usmjeriti prema potrebama gospodarstva. Ova industrijska grana već neko vrijeme ističe potrebu za stručnom radnom snagom i velikim mogućnostima zapošljavanja.

Automatizacijom i novim tehnologijama tvrtke omogućavaju veću produktivnost, ali i bolju kvalitetu. $U$ doba digitalizacije i automatizacije poslovanja, kao dijela Industrije 4.0., u daljim razvojnim planovima poslovanja bit će neizbježno staviti prioritet na promjene poslovnih modela koje će digitalizacija donijeti te se suočiti s izazovima koje će tradicionalna industrija morati nadvladati.

Inovacije, istraživanje i stručno obrazovan kadar ključ su uspjeha svake industrije.

\section{Literatura}

[1] Odluka o nacionalnoj klasifikaciji djelatnosti 2007.-NKD 2007, NN 58/2007, Broj dokumenta u izdanju: 1870, 6.6.2007. (https:// narodne novine.nn.hr/clanci/sluzbeni/2007_06_58_1870.html)

[2] https://www.dzs.hr/, pristupljeno 12. 12. 2018.

[3] HGK, Sektor za industriju, A. Torbarina, Tekstilni dani, prosinac [4] https://www.hgk.hr/digitalna-komora, pristupljeno 15. 12. 2018.

[5] Anić, I.D. i sur. 2007. Strateške odrednice razvoja industrije tekstila i odjeće u Republici Hrvatskoj za razdoblje od 2006. do 2015. Ekonomski institut Zagreb, Zagreb. ISBN 978-953-6030$36-1$ 
Tablica 5 Uvoz i izvoz u tisućama €-a prerađivačke industrije za razdoblje I.-VII. 2019. i I.-VII. 20120 (djelatnost C15)

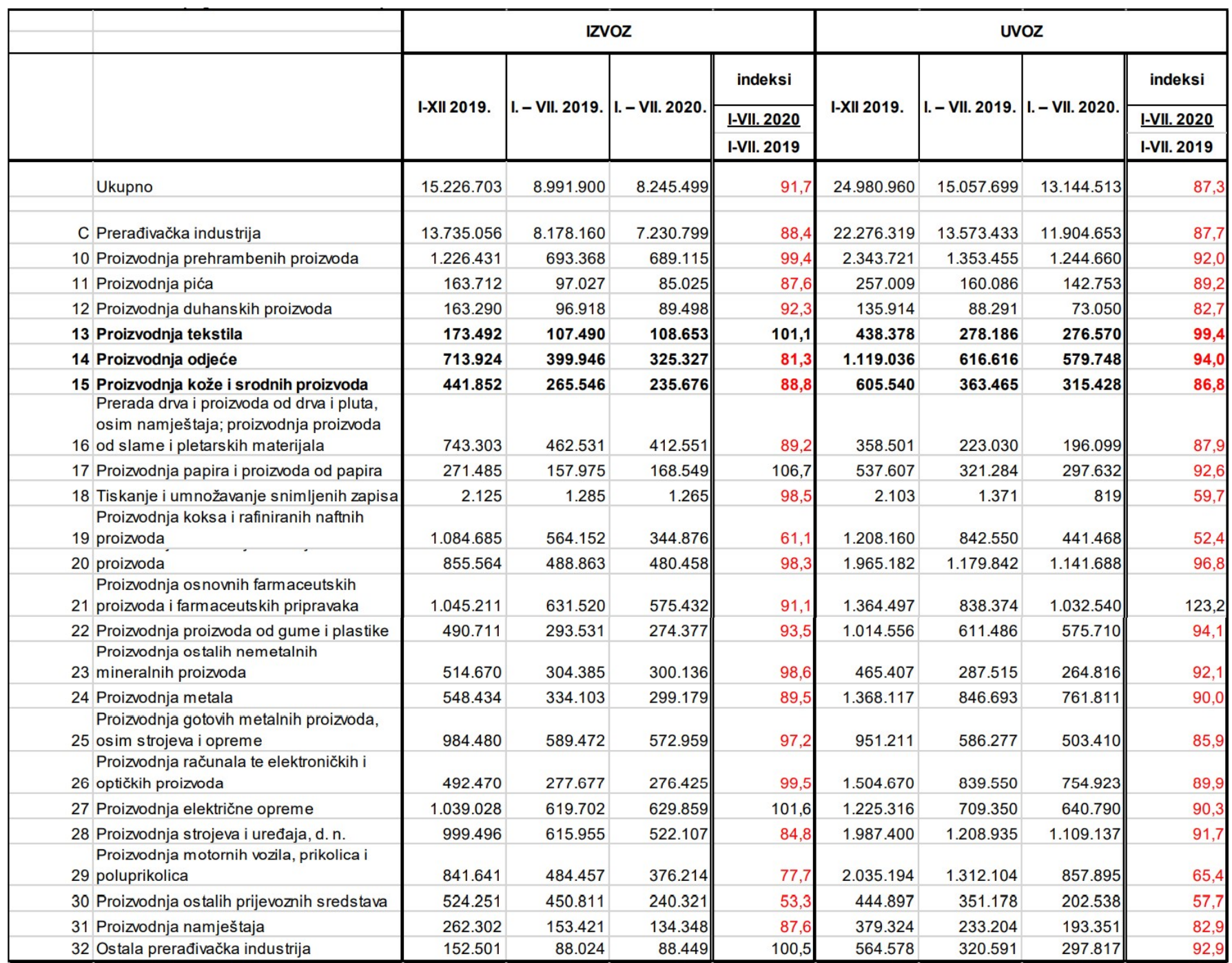

